\title{
Study of the nutrient and plankton dynamics in Lake Tanganyika using a reduced-gravity model
}

\author{
Jaya Naithani ${ }^{a, *}$, François Darchambeau ${ }^{b}$, Eric Deleersnijder ${ }^{c}$, \\ Jean-Pierre Descy ${ }^{b}$, Eric Wolanski ${ }^{d}$ \\ a Université catholique de Louvain, Institut d'astronomie et de géophysique Georges Lemaître, \\ Chemin du Cyclotron 2, B-1348 Louvain-La-Neuve, Belgium \\ ${ }^{\mathrm{b}}$ Facultés Universitaires Notre-Dame de la Paix, Laboratoire d’Ecologie des Eaux Douces, Rue de Bruxelles 61, B-5000 Namur, Belgium \\ c Université catholique de Louvain, Institut d'astronomie et de géophysique Georges Lemaître and Centre for systems engineering and \\ applied mechanics, 4 Avenue Georges Lemaître, B-1348 Louvain-La-Neuve, Belgium \\ d Australian Institute of Marine Science, PMB No. 3, Townsville MC, Qld. 4810, Australia
}

\section{A R T I C L E I N F O}

Article history:

Received 9 August 2005

Received in revised form

11 July 2006

Accepted 19 July 2006

Published on line 18 September 2006

Keywords:

Lake Tanganyika

Ecological modelling

Plankton productivity

\begin{abstract}
A B S T R A C T
An eco-hydrodynamic (ECOH) model is proposed for Lake Tanganyika to study the plankton productivity. The hydrodynamic sub-model solves the non-linear, reduced-gravity equations in which wind is the dominant forcing. The ecological sub-model for the epilimnion comprises nutrients, primary production, phytoplankton biomass and zooplankton biomass. In the absence of significant terrestrial input of nutrients, the nutrient loss is compensated for by seasonal, wind-driven, turbulent entrainment of nutrient-rich hypolimnion water into the epilimnion, which gives rise to high plankton productivity twice in the year, during the transition between two seasons. Model simulations predict well the seasonal contrasts of the measured physical and ecological parameters. Numerical tests indicate that the half saturation constant for grazing by zooplankton and the fish predation rate on zooplankton affect the zooplankton biomass measurably more than that of phytoplankton biomass. This work has implications for the application of this model to predict the climatological biological productivity of Lake Tanganyika.
\end{abstract}

(c) 2006 Elsevier B.V. All rights reserved.

\section{Introduction}

Lake Tanganyika (Fig. 1) is the third largest inland water body in the world after the Caspian Sea and Lake Baikal. It plays a vital role in the economy and food source of the surrounding riparian nations. It is a meromictic tropical lake: complete overturning of the water never takes place and mixing occurs only partially. The upper layer undergoes seasonal temperature change annually, while the hypolimnion is anoxic with an invariant temperature. The latter is a vast reservoir of nutrients largely isolated from surface influences.
The lake remains stratified all year long. In the dry season (April/May-August/September) the strong southeasterly winds deepen the surface layer and the thermocline oscillates during the whole year (Coulter and Spigel, 1991; Naithani et al., 2002, 2003). The lake is highly transparent (Coulter and Spigel, 1991). Off shore Secchi depth, a measure of transparency, increased from a mean depth of 6.1-15.5 m between 1913 and 1947 (Verburg et al., 2003). During the present CLIMLAKE project the Secchi depth was $13 \mathrm{~m}$ off Kigoma and 6-17 $\mathrm{m}$ off Mpulungu (Descy and Gosselain, 2004, p. 20). The lake receives solar radiation for the whole year without much seasonal-

\footnotetext{
* Corresponding author. Tel.: +32 10473300; fax: +32 10474722.

E-mail address: naithani@astr.ucl.ac.be (J. Naithani). 


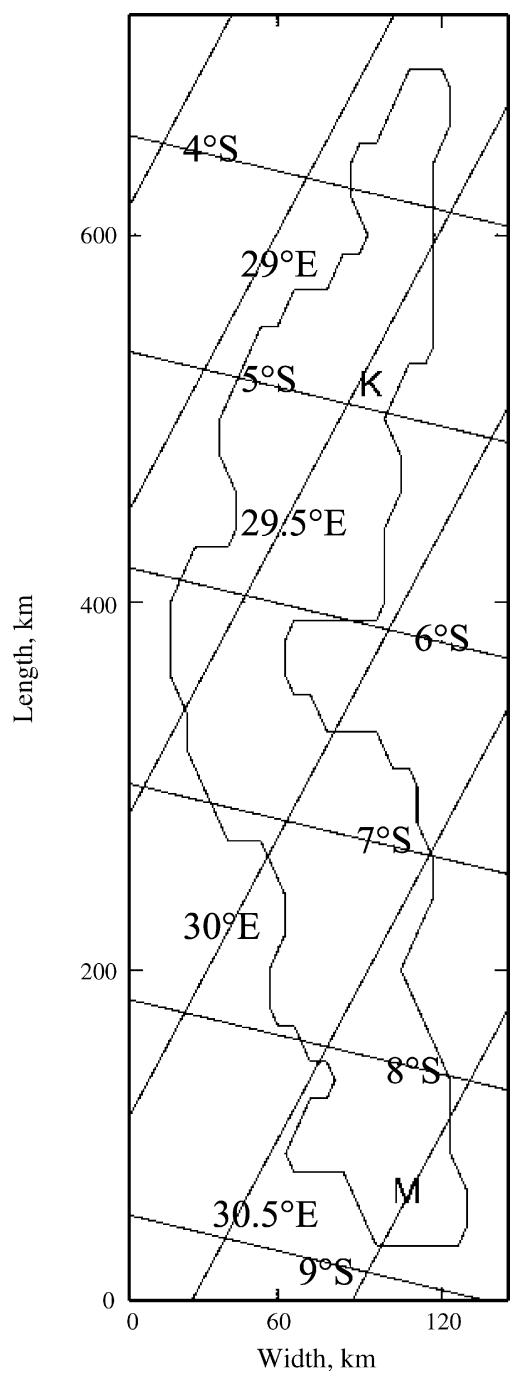

Fig. 1 - Map of Lake Tanganyika used in the model with $6 \mathrm{~km} \times 20 \mathrm{~km}$ resolution in the $x$ and $y$ direction, respectively. $M$ and $K$ indicate the sites used in the study off Mpulungu and off Kigoma, respectively.

ity (Coulter and Spigel, 1991). While nutrient recycling in the upper euphotic layer takes place throughout the year, the supply of nutrients is often a limiting factor for algal growth (Edmond et al., 1993; Hecky et al., 1993; Järvinen et al., 1999). The nutrient loading is mainly internal nutrients from within the lake; riverine or atmospheric input of nutrients is considered negligible for Lake Tanganyika (Hecky and Fee, 1981; Sarvala et al., 1999; Langenberg et al., 2003a). Because of its great depth, Lake Tanganyika is like the ocean in that most of the nutrients in the system are in the deep water, and nutrient supply to the mixed layer, where photosynthesis can occur, is dependent on vertical mixing processes (Hecky and Fee, 1981; Hecky et al., 1991). Nutrients from the hypolimnion are supplied to the epilimnion mainly by wind-driven upwelling of the strong southeast winds during the dry season (Hecky et al., 1991; Langenberg et al., 2003b; Verburg and Hecky, 2003). This upwelling results in the seasonal enhancement of the nutrients in the euphotic layer. During the wet season, the primary production is smaller and is primarily dependent on the nutrients regenerated within the epilimnion (Coulter and Spigel, 1991).

In this paper the above mentioned hydrodynamic, thermodynamic and ecological processes are incorporated into an eco-hydrodynamic model to study the primary productivity of Lake Tanganyika. Numerical simulations of the primary food web are carried out including one nutrient, phytoplankton biomass and zooplankton biomass. Nutrient is mainly being supplied to the epilimnion from the hypolimnion due to entrainment, river and rain inputs are not considered. The hydrodynamic model comprises non-linear, reduced-gravity equations. Handoh and Bigg (2001) have used this type of model to study the primary productivity in the tropical open ocean. The hydrodynamic sub-model successfully simulates the period and amplitude of the thermocline oscillations, their origin and internal Kelvin waves in the lake (Naithani et al., 2002, 2003; Naithani and Deleersnijder, 2004).

Literature abounds with lake ecosystem models developed during the last few decades. These models range from the over simplified input-output models to more complex 1-dimensional and fully developed 3-dimensional models (Reynolds and Irish, 1997; Ahlgren et al., 1998; Krivtsov et al., 1998; Karagounis et al., 1993; Bonnet and Wessen, 2001). Jorgensen and Bendoricchio (2001) give an overview of several models of different levels of complexity. An existing model needs recalibration and often changes in model structure if applied to other lakes (Jorgensen et al., 1986; Hamilton and Schladow, 1997; Pers and Persson, 2003; Mieleitner and Reichert, 2006). Since hydrodynamics of Lake Tanganyika was already studied extensively using the non-layer reducedgravity model developed for the purpose. It was decided to develop a simple ecosystem model to be coupled to the hydrodynamic model of Lake Tanganyika. The hydrodynamic model was modified to accommodate the exchange of water between hypolimnion and epilimnion through entrainment and detrainment during upwellings and downwellings, respectively.

\section{Eco-hydrodynamic (ECOH) model of Lake Tanganyika}

The model consists of a hydrodynamic component, thermodynamic component and an ecological module.

\subsection{Hydrodynamic sub-model}

The hydrodynamic sub-model is the modified version of the non-linear, two-layer, reduced-gravity model developed for Lake Tanganyika and used in earlier studies (Naithani et al., 2002, 2003; Naithani and Deleersnijder, 2004). Here we have included entrainment and detrainment terms. Hypolimnion water is entrained into the upper layer in the upwelling regions during strong winds, and is detrained in the downwelling regions. The epilimnion water budget equation is:

$\frac{\partial \xi}{\partial t}+\frac{\partial(\mathrm{Hu})}{\partial x}+\frac{\partial(\mathrm{Hu})}{\partial y}=w_{\mathrm{e}}$ 
where $x$ and $y$ are horizontal axes, $u$ and $v$ are the depth integrated velocity components in the surface layer in the $x$ and $y$ directions, $t$ is the time, $\xi$ is the downward displacement of the thermocline, $\mathrm{H}=h+\xi$ is the thickness of the epilimnion (the surface, well-mixed layer), $h$ is the reference depth of the upper layer $(m)$ and $w_{\mathrm{e}}$ is the entrainment velocity $\left(\mathrm{m} \mathrm{s}^{-1}\right)$ defined as:

$w_{e}=\left(\frac{3}{20}\right)^{1 / 2} \frac{\left(\tau_{x}^{2}+\tau_{y}^{2}\right)^{1 / 2}}{(\varepsilon g H)^{1 / 2}}-w_{d}-\frac{\xi}{r_{t t}}$

where the first term on the right hand side of Eq. (2) is inspired by Price (1979), $\tau_{x}$ and $\tau_{y}$ are horizontal components of specific wind stress in $x$ and $y$ direction $\left(\mathrm{m}^{2} \mathrm{~s}^{-2}\right), \varepsilon=\left(\rho_{\mathrm{b}}-\rho_{\mathrm{s}}\right) / \rho_{\mathrm{b}}$, is the relative density difference between the hypolimnion $\left(\rho_{\mathrm{b}}\right)$ and the epilimnion $\left(\rho_{\mathrm{s}}\right)$ respectively, $w_{\mathrm{d}}$ is the detrainment term $\left(\mathrm{m} \mathrm{s}^{-1}\right) . w_{\mathrm{d}}$ is defined such that the annual mean of the epilimnion volume remains approximately constant. There are large uncertainties in the parameterization of entrainment and detrainment terms. As a consequence, to avoid occasional occurrence of spurious values of $\xi$, a relaxation term $\left(\xi / r_{t t}\right)$ is needed which slowly nudges the upper layer depth toward its equilibrium position. The relaxation timescale, $r_{t t}$, is sufficiently long so that the relaxation term is generally smaller than the entrainment and detrainment terms. $w_{\mathrm{e}}$ is positive (negative) in the upwelling (downwelling) regions where water is entrained into (detrained from) the upper layer.

The momentum equations are:

$$
\begin{aligned}
\frac{\partial(\mathrm{Hu})}{\partial t} & +\frac{\partial(\mathrm{Huu})}{\partial x}+\frac{\partial(\mathrm{Huu})}{\partial y}-f H v=-g H \frac{\partial \varepsilon \xi}{\partial x} \\
& +\frac{\partial}{\partial x}\left(\mathrm{HA}_{x} \frac{\partial u}{\partial x}\right)+\frac{\partial}{\partial y}\left(\mathrm{HA}_{y} \frac{\partial u}{\partial y}\right)+\frac{\tau_{x}}{\rho_{0}}+w_{\mathrm{e}}^{-} u
\end{aligned}
$$

$$
\begin{aligned}
\frac{\partial(\mathrm{Hv})}{\partial \mathrm{t}} & +\frac{\partial(\mathrm{Huv})}{\partial x}+\frac{\partial(\mathrm{Huv})}{\partial y}+f H u=-g H \frac{\partial \varepsilon \xi}{\partial y} \\
& +\frac{\partial}{\partial x}\left(\mathrm{HA}_{x} \frac{\partial v}{\partial x}\right)+\frac{\partial}{\partial y}\left(\mathrm{HA}_{\mathrm{y}} \frac{\partial v}{\partial y}\right)+\frac{\tau_{y}}{\rho_{0}}+w_{\mathrm{e}}^{-} v
\end{aligned}
$$

where $f$ is the Coriolis factor ( $<0$ in the southern hemisphere), $A_{s}$ is the horizontal eddy viscosity in the $s(=x, y)$ direction, $w_{\mathrm{e}}^{-}=w_{\mathrm{e}}-\left|w_{\mathrm{e}}\right| / 2$ is the negative part of the entrainment velocity, i.e. $w_{\mathrm{e}}^{-}$is equal to $w_{\mathrm{e}}$ if $w_{\mathrm{e}}<0$ and is zero otherwise. Below, use will be made of the positive part of the entrainment velocity, which is defined as $w_{\mathrm{e}}^{+}=w_{\mathrm{e}}+\left|w_{\mathrm{e}}\right| / 2$.

\subsection{Thermodynamic sub-model}

The surface layer temperature is predicted using the equation:

$$
\begin{aligned}
\frac{\partial(\mathrm{H} \theta)}{\partial t} & +\frac{\partial(\mathrm{Hu} \theta)}{\partial x}+\frac{\partial(\operatorname{Hv} \theta)}{\partial y}=\frac{\partial}{\partial x}\left(H K_{x} \frac{\partial \theta}{\partial x}\right)+\frac{\partial}{\partial y}\left(H K_{y} \frac{\partial \theta}{\partial y}\right) \\
& +w_{\mathrm{e}}^{+} \theta_{\mathrm{h}}+w_{\mathrm{e}}^{-} \theta+H \frac{\left(\theta_{\mathrm{s}}-\theta\right)}{r_{\mathrm{ts}}}
\end{aligned}
$$

where $\theta$ is the surface layer temperature, $\theta_{\mathbf{S}}$ is the reference temperature of the surface layer, $\theta_{\mathrm{h}}$ is the temperature of the hypolimnion water and $r_{\mathrm{ts}}$ is the relaxation time scale for surface fluxes.

\subsection{Ecological sub-model}

The ecological sub-model (Fig. 2) simulates nutrient fluxes between dissolved inorganic pools and a simplified 3compartment trophic chain (phytoplankton - herbivorous zooplankton - planktivorous fish). Fluxes of carbon (C) and phosphorus $(\mathrm{P})$ are modeled. Each scalar variable $\mathrm{X}$ (nutrients,

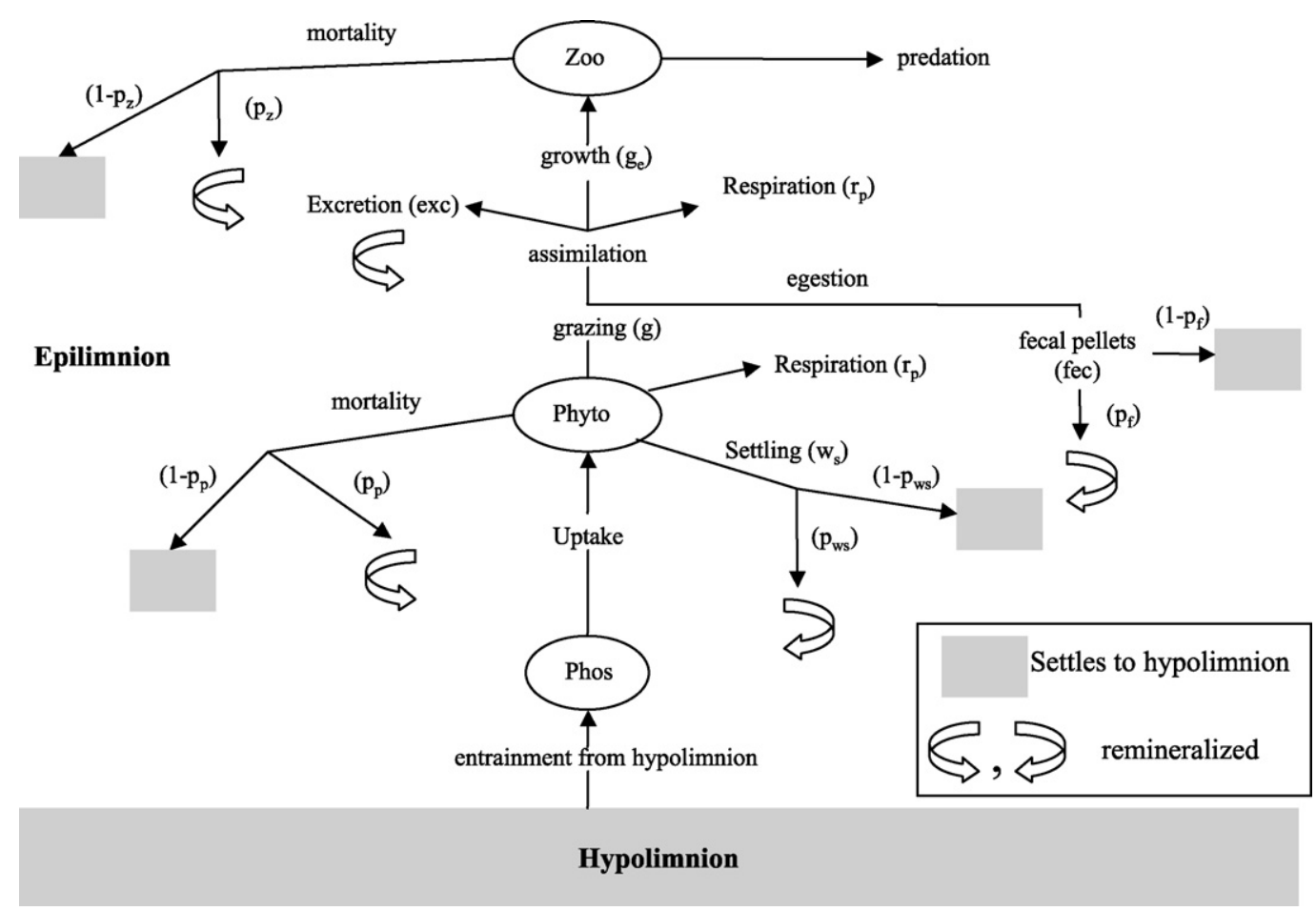

Fig. 2 - Flow diagram of the ecological parameters considered in the model. 
phytoplankton and zooplankton) is modelled using the conservation equation:

$$
\begin{aligned}
\frac{\partial(H X)}{\partial t} & +\frac{\partial(H u X)}{\partial x}+\frac{\partial(H v X)}{\partial y}=H(G-D)_{X} \\
& +\frac{\partial}{\partial x}\left(H K_{X} \frac{\partial X}{\partial x}\right)+\frac{\partial}{\partial y}\left(H K_{y} \frac{\partial X}{\partial y}\right)+\phi_{\text {he }}
\end{aligned}
$$

$\phi_{\mathrm{he}}=w_{\mathrm{e}}^{-} X_{\mathrm{h}}+w_{\mathrm{e}}^{-} X$

where $X$ is the concentration of the respective ecological parameter in the epilimnion $(G-D)_{X}$ is the growth/destruction term for the corresponding variable $(X), K_{S}$ is the horizontal eddy diffusivity in the $s(=x, y)$ direction, $\phi_{\text {he }}$ is the flux of $X$ from the hypolimnion to the epilimnion, $X_{h}$ is the value of $X$ in the hypolimnion and vice-versa.

\subsubsection{Phytoplankton}

The source/sink term for the phytoplankton carbon biomass evolution is:

$(G-D)_{\text {Phyto }}=\left(\mu-r_{p}-m_{p}-w_{s}\right)$ Phyto - grZoo

where Phyto is the phytoplankton carbon biomass ( $\mu \mathrm{g} \mathrm{C} / \mathrm{L}$ ), $\mu$ is the daily growth rate $\left(\mathrm{d}^{-1}\right), r_{\mathrm{p}}$ is the loss due to respiration $\left(\mathrm{d}^{-1}\right), m_{\mathrm{p}}$ is the mortality loss $\left(\mathrm{d}^{-1}\right), w_{\mathrm{s}}$ is the settling rate $\left(\mathrm{m} \mathrm{d}^{-1}\right), g_{\mathrm{r}}$ is the loss due to grazing by zooplankton $\left(\mathrm{d}^{-1}\right)$ and Zoo is the zooplankton carbon biomass ( $\mu \mathrm{gC} / \mathrm{L})$. The phytoplankton daily growth rate is:

$\mu=\mu_{\max } f(P)$

where $\mu_{\max }=2 P_{\max } f(I)$ is the maximum photosynthetic production, $P_{\max }$ is the maximum carbon-specific photosynthetic rate, $f(I)$ is the light limitation factor and $f(P)$ is the phosphorus limitation factor. $F(P)$ is defined according to Michaelis and Menten kinetics:

$f(P)=\frac{\text { Phos }}{\text { phos }+k_{\text {phos }}}$

where Phos is the concentration of the dissolved phosphate $(\mu \mathrm{gP} / \mathrm{L})$ and $k_{\text {phos }}$ is the half saturation constant for growth.

The light limitation is defined as:

$f(I)=\left(\frac{1}{k_{\mathrm{e}} H}\right)\left[\arctan \left(\frac{I_{0}}{2 I_{k}}\right)-\arctan \left(I_{0} e^{-k_{e} H / 2 I_{k}}\right)\right]$

where $k_{\mathrm{e}}=0.07 \mathrm{Phyto} / 100+0.066$ is the extinction coefficient based on field data (Fig. 3), $I_{k}$ is the light saturation constant and $I_{0}$ is the solar insolation reaching the surface of the lake or the photosynthetically active radiation (PAR). Gross primary production, GP is defined as:

$\mathrm{GP}=2 \mathrm{P}_{\max } f(\mathrm{I}) \mathrm{z}_{\mathrm{eu}}$ Phyto

where $z_{\mathrm{eu}}=4.6 / k_{\mathrm{e}}$ is the euphotic depth.

The grazing rate, $g_{\mathrm{r}}$ is defined as:

$g_{\mathrm{r}}=g_{\mathrm{max}}$ as Phyto $\rightarrow$ ILL

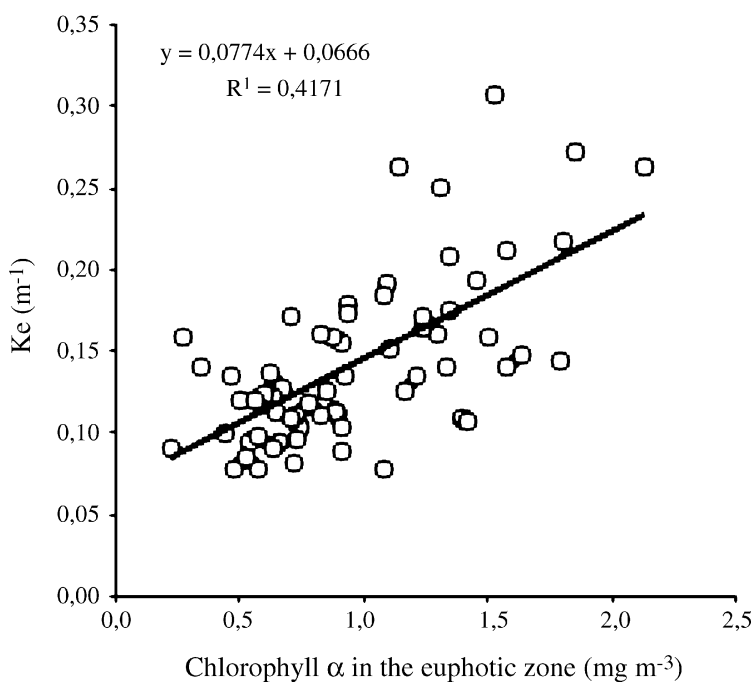

Fig. 3 - Linear regression of light extinction coefficient $\left(\mathrm{m}^{-1}\right)$ against chlorophyll a concentration $\left(\mathrm{mg} \mathrm{m}^{-3}\right)$ in the euphotic zone.

$g_{\mathrm{r}}=g_{\mathrm{max}} \frac{\text { Phyto }}{\text { Phyto }+k_{\text {phyto }}}$ for Phyto $>$ Phyto $_{\min }$

$g_{\mathrm{r}}=0$ for Phyto $\leq$ Phyto $_{\min }$

where $g_{\max }$ is the maximum grazing rate per day, ILL is the incipient limiting level, Phyto min $_{\text {in }}$ is the threshold below which zooplankton do not graze and $k_{\text {phyto }}$ is half-saturation constant for grazing.

\subsubsection{Zooplankton}

The source/sink term for the zooplankton carbon biomass evolution is:

$(G-D)_{\text {Zoo }}=\left(\mu_{z}-m_{z}\right) Z o o-p F$

where Zoo is the zooplankton carbon biomass ( $\mu \mathrm{gC} / \mathrm{L}), \mu_{\mathrm{z}}$ is the daily growth rate, $m_{z}$ is the loss due to mortality $\left(d^{-1}\right), p$ is the predation rate by zooplanktivorous fishes $\left(\mathrm{d}^{-1}\right)$ and $F$ is the zooplanktivorous fish biomass.

The zooplankton growth rate, $\mu_{z}$ depends on zooplankton grazing rate. A fraction, $g_{\mathrm{a}}$ of the ingested food is assimilated through the gut wall, while the rest is egested as fecal pellets (Elser et al., 1995). Metabolic requirements consume a fraction, $g_{\mathrm{m}}$ of the assimilated carbon. The elements not respired are incorporated into new biomass. The zooplankton growth rate is modelled by:

$\mu_{\mathrm{z}}=\left(1-g_{\mathrm{m}}\right) g_{\mathrm{a}} g_{\mathrm{r}}$

where $\left(1-g_{\mathrm{m}}\right) \cdot g_{\mathrm{a}}\left(=g_{\mathrm{e}}\right)$ is the growth efficiency of zooplankton. The zooplanktivorous fish biomass is assumed equal to that of zooplankton biomass (Sarvala et al., 1999) and the predation rate is:

$p=\operatorname{pred}_{\max } \frac{\mathrm{Zoo}}{\mathrm{ZoO}+k_{\mathrm{zoo}}}$ for Zoo $>\mathrm{ZoO}_{\min }$

$p=0$ for $\mathrm{Z} \circ \circ<\mathrm{Zoo}_{\min }$ 
where pred $_{\max }$ is the maximum predation rate $\left(\mathrm{d}^{-1}\right), \mathrm{Zoo}_{\min }$ is the zooplankton biomass below which predation ceases and $k_{\text {zoo }}$ is the half-saturation constant for predation. Settling is not included in the model, because zooplankton is mobile and can swim to avoid sinking into the hypolimnion (Jorgensen and Bendoricchio, 2001).

In the model, recycling of phosphate, $\mathrm{P}$ from zooplankton grazing process comes from two sources: the remineralization of fecal matter and the excretion of excess $P$. The amount, $F_{f}$ of $\mathrm{P}$ egested from the gut and recycled in the water column is defined as:

$F_{\mathrm{f}}=p_{\mathrm{f}}\left(1-g_{\mathrm{a}}\right) \frac{g_{\mathrm{r}}}{\mathrm{C}: \mathrm{P}_{\text {phyto }}}$

where $p_{f}$ is the recycled fraction of egested $P$. The amount of $P$ assimilated in excess is directly excreted by zooplankton in a dissolved form. This amount $E$ is defined by:

$E=\left(\frac{g_{\mathrm{a}}}{\mathrm{C}: \mathrm{P}_{\text {phyto }}}-\frac{g_{\mathrm{e}}}{\mathrm{C}: \mathrm{P}_{\text {zoo }}}\right) g_{\mathrm{r}}$

\subsubsection{Nutrients}

As discussed in the introduction only the nutrient entrained from hypolimnion is considered. Nutrient inputs from river and rain have not been considered. Only phosphorus is modeled, as it appeared from observations on seston stoichiometry that $\mathrm{C}: \mathrm{P}$ and $\mathrm{N}: \mathrm{P}$ ratios indicated more frequent instances of phosphorus limitation than nitrogen limitation (data not shown). Previous studies have shown that phosphorus is the nutrient most likely to limit phytoplankton growth in Lake Tanganyika (Järvinen et al., 1999). Time evolution of phosphate in the model is determined by uptake by phytoplankton, remineralization of dead phytoplankton and zooplankton, zooplankton egestion and excretion. A percentage $p_{\mathrm{ws}}, p_{\mathrm{p}}, p_{\mathrm{z}}$ and $p_{f}$, respectively of settling phytoplankton, dead phytoplankton, dead zooplankton and fecal pellets are directly recycled. Therefore,

$$
\begin{aligned}
(G-D)_{\text {Phos }}= & -\mu \frac{\text { Phyto }}{(\mathrm{C}: \mathrm{P})_{\text {phyto }}}+p_{\mathrm{ws}} w_{\mathrm{s}} \frac{\text { Phyto }}{(\mathrm{C}: \mathrm{P})_{\text {phyto }}} \\
& +p_{\mathrm{p}} m_{\mathrm{p}} \frac{\text { Phyto }}{(\mathrm{C}: \mathrm{P})_{\text {phyto }}}+p_{\mathrm{z}} m_{\mathrm{z}} \frac{\mathrm{Zoo}}{(\mathrm{C}: \mathrm{P})_{\text {zoo }}}+E_{\mathrm{Zoo}}+F_{f} \text { Zoo }
\end{aligned}
$$

where Phos is the dissolved phosphate pool ( $\mu \mathrm{gP} / \mathrm{L})$.

\section{Observations}

Observations, used for validating the model, were collected in the framework of the CLIMLAKE project (Climate variability as recorded in Lake Tanganyika), during 2002-2003 (Descy and Gosselain, 2004; Descy et al., 2005). Sampling sites for the data used in this work are at $4^{\circ} 50.9^{\prime}$ S; $29^{\circ} 35^{\prime} \mathrm{E}$ off Kigoma and $8^{\circ} 43.9^{\prime} \mathrm{S} ; 31.4^{\circ} 2^{\prime} \mathrm{E}$ off Mpulungu. Samples were collected fortnightly at every 20-100 m depth. Methods for limnological, chemical and biological measurements have been detailed in Descy and Gosselain (2004) and Descy et al. (2005). Following measurements are used:
- depth of the mixed layer (determined from vertical CTD profiles),

- soluble reactive phosphorus (SRP) averaged for the euphotic zone,

- phytoplankton biomass in the mixed layer, from vertical profiles chlorophyll $a$, converted to phytoplankton carbon using a C:chlorophyll a ratio of 100 , obtained from linear regression of chlorophyll a versus seston organic carbon (Descy and Gosselain, 2004);

- zooplankton biomass, estimated from counts of adult copepods on $100 \mu \mathrm{m}$ mesh plankton net samples from 0 to $100 \mathrm{~m}$, converted to dry weight and then to zooplankton carbon.

\section{Results}

\subsection{Model forcings}

The parameters, variables and constants used in the model are listed in Table 1 along with their values used in the present work. The hydrodynamic model was initialized with wind forcing obtained from NCEP. The near surface wind data for $30^{\circ} \mathrm{E}, 7.5^{\circ} \mathrm{S}$ were used to calculate the two-components of the wind stress. The wind-stress was assumed to be uniform over the whole lake. Fig. 4 shows the time series plots of the horizontal wind, photosynthetically active radiation (PAR) and the surface wind-stress during 2002-2003. In the year 2002 the winds were stronger over a longer period than in 2003.

\subsection{Model simulations}

Fig. 5a and $\mathrm{b}$ show the time series of observed and predicted mixed-layer (epilimnion) depth, and the depth-averaged concentration in the epilimnion of phosphate, the phytoplankton gross production, the phytoplankton and zooplankton biomass at Mpulungu and Kigoma (see a location map in Fig. 1), respectively. The physical model simulated well the surface layer depth, its increase during the dry season and
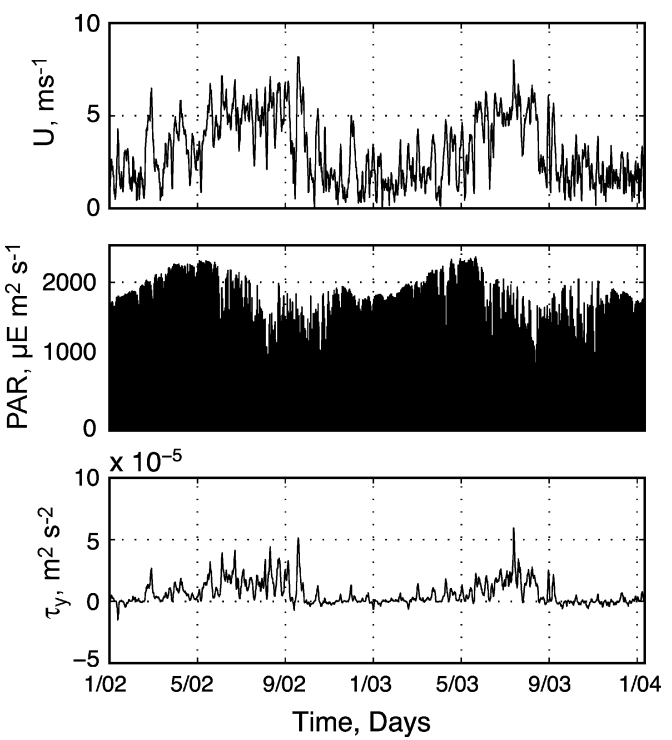

Fig. 4 - NCEP reanalysed horizontal wind speed, PAR and the $y$-component of wind-stress. 
Table 1 - Parameters, variables and constants used in the numerical model

\begin{tabular}{|c|c|c|c|}
\hline Name & Units & Value & Description \\
\hline$\Delta_{\mathrm{x}}$ & $\mathrm{m}$ & 6000.0 & Grid size in $x$ direction \\
\hline$\Delta y$ & $\mathrm{~m}$ & 20000.0 & Grid size in y direction \\
\hline$\Delta_{\mathrm{t}}$ & $\mathrm{s}$ & 1800 & Time step \\
\hline$h$ & $\mathrm{~m}$ & 30 & Reference depth of the thermocline \\
\hline$\theta_{\mathrm{b}}$ & ${ }^{\circ} \mathrm{C}$ & 24.5 & Average temperature of the bottom layer \\
\hline$\theta_{\mathrm{s}}$ & ${ }^{\circ} \mathrm{C}$ & 27.0 & Average reference temperature of the surface layer \\
\hline Phyto & $\mu \mathrm{gC} / \mathrm{L}$ & Variable & Phytoplankton biomass in the epilimnion \\
\hline Phyto $_{h}$ & $\mu \mathrm{gC} / \mathrm{L}$ & 0.0 & Phytoplankton biomass in the hypolimnion \\
\hline Phyto $\min$ & $\mu g \mathrm{C} / \mathrm{L}$ & 15.0 & Minimum phytoplankton biomass in the epilimnion \\
\hline$k_{\text {phyto }}$ & $\mu g \mathrm{C} / \mathrm{L}$ & 30.0 & Half saturation constant for grazing by zooplankton \\
\hline ILL & $\mu g \mathrm{C} / \mathrm{L}$ & 60.0 & Incipient limiting level \\
\hline$w_{\mathrm{s}}$ & $\mathrm{md}^{-1}$ & 1.0 & Settling velocity of phytoplankton \\
\hline$m_{\mathrm{p}}$ & $d^{-1}$ & 0.11 & Mortality rate of phytoplankton \\
\hline$r_{\mathrm{p}}$ & $d^{-1}$ & $0.085 \times P_{\max }$ & Respiration rate of phytoplankton \\
\hline$P_{\max }$ & $d^{-1}$ & 1.4 & Maximum carbon specific photosynthetic rate \\
\hline$k_{\text {phos }}$ & $\mu g \mathrm{C} / \mathrm{L}$ & 1.0 & Half saturation constant for growth of phytoplankton \\
\hline$I_{k}$ & $\mu \mathrm{molE} \mathrm{m} \mathrm{m}^{-2} \mathrm{~s}^{-1}$ & 350 & Light saturation constant \\
\hline$g_{\max }$ & $d^{-1}$ & 0.5 & Maximum grazing rate \\
\hline$C: P_{\text {phyto }}$ & & 58.1 & Carbon to phosphorus ratio in phytoplankton \\
\hline Zoo & $\mu \mathrm{gC} / \mathrm{L}$ & Variable & Zooplankton biomass in the epilimnion \\
\hline $\mathrm{ZoO}_{\mathrm{h}}$ & $\mu g \mathrm{C} / \mathrm{L}$ & 0.0 & Zooplankton biomass in the hypolimnion \\
\hline $\mathrm{Zoo}_{\min }$ & $\mu g \mathrm{C} / \mathrm{L}$ & 2.0 & Minimum zooplankton biomass in the epilimnion \\
\hline$k_{\mathrm{Zoo}}$ & $\mu g \mathrm{C} / \mathrm{L}$ & 5.5 & Half saturation constant for predation by zooplanktivorous fish \\
\hline$p_{\mathrm{ws}}$ & & 0.5 & Percentage of remineralized settling phytoplankton \\
\hline$p_{\mathrm{p}}$ & & 0.5 & Percentage of remineralized dead phytoplankton \\
\hline$p_{z}$ & & 0.5 & Percentage of remineralized dead zooplankton \\
\hline$p_{\mathrm{f}}$ & & 0.3 & Percentage of remineralized fecal material \\
\hline$p_{\max }$ & $d^{-1}$ & 0.08 & Maximum predation rate \\
\hline$m_{z}$ & $d^{-1}$ & 0.07 & Zooplankton mortality rate \\
\hline$g_{\mathrm{e}}$ & & 0.32 & Growth efficiency of zooplankton \\
\hline C:P $P_{\text {Zoo }}$ & & 77.42 & Carbon to phosphorus ratio in zooplankton \\
\hline Phos & $\mu g \mathrm{P} / \mathrm{L}$ & Variable & Phosphorus concentration in the epilimnion \\
\hline $\mathrm{Phos}_{\mathrm{h}}$ & $\mu g \mathrm{P} / \mathrm{L}$ & 30.0 & Phosphorus concentration in the hypolimnion \\
\hline $\mathrm{Phos}_{\min }$ & $\mu g \mathrm{P} / \mathrm{L}$ & 1.0 & Minimum concentration of phosphorus of zooplankton in the epilimnion \\
\hline
\end{tabular}

decrease at the end. The ecological model predicts well the upwelling of nutrients at the beginning of the dry season and their decrease at the end. The model simulates satisfactorily the onset and the magnitude of the phytoplankton increase at the beginning of the dry season, its decrease in the middle of the season and its second increase at the end of the dry season. The minimum values during the wet season are also well predicted by the model. Furthermore, the model reproduces well the north-south gradient in the magnitude of each variable. Most of the simulated parameters show a reasonably good correlation with the measurements.

\subsection{Sensitivity tests}

Model sensitivity was tested for two parameters, which appear most critical, $k_{\text {phyto }}$ and predator biomass. Table 2 shows the percentage change in the ecological parameters during the sensitivity tests. Fig. 6 shows the results of numerical tests performed to study the influence of the half-saturation constant for grazing, $k_{\text {phyto }}$ on the variability of phytoplankton and zooplankton biomass off Kigoma and Mpulungu, respectively. Increasing (decreasing) the half-saturation constant for grazing decreased (increased) the zooplankton biomass and increased (decreased) phytoplankton biomass. The change in the phytoplankton biomass is almost half the change in the zooplankton biomass.
Reliable data are unavailable on predator abundance though it appears that the biomass of zooplanktivorous fish is about equal to that of zooplankton (Sarvala et al., 1999). In the model simulations, the zooplanktivorous fish biomass was set equal to that of zooplankton biomass. In order to estimate the sensitivity of this assumption on the food web, the zooplanktivorous fish biomass was varied, the results of this sensitivity tests are shown in Table 2 and Fig. 7. A $25 \%$ decrease of zooplanktivorous fish biomass increased the zooplankton biomass by around 35\%. When the zooplanktivorous fish biomass was set equal to half the zooplankton biomass, the latter increased by $100 \%$ and a $25 \%$ increase of zooplantivorous fish biomass decreased the zooplankton biomass by around $13 \%$. For these tests with the predator population the change in the phytoplankton biomass is much less than the change in the zooplankton biomass.

\section{Discussion}

The surface layer depth starts increasing at the beginning of the dry season because of wind driven mixing and remain at greater depth during the whole season. It decreases at the end of the dry season and remain more of less at this depth during the wet season until the beginning of the next dry season. Phosphorus concentration, likewise, starts increasing with the 

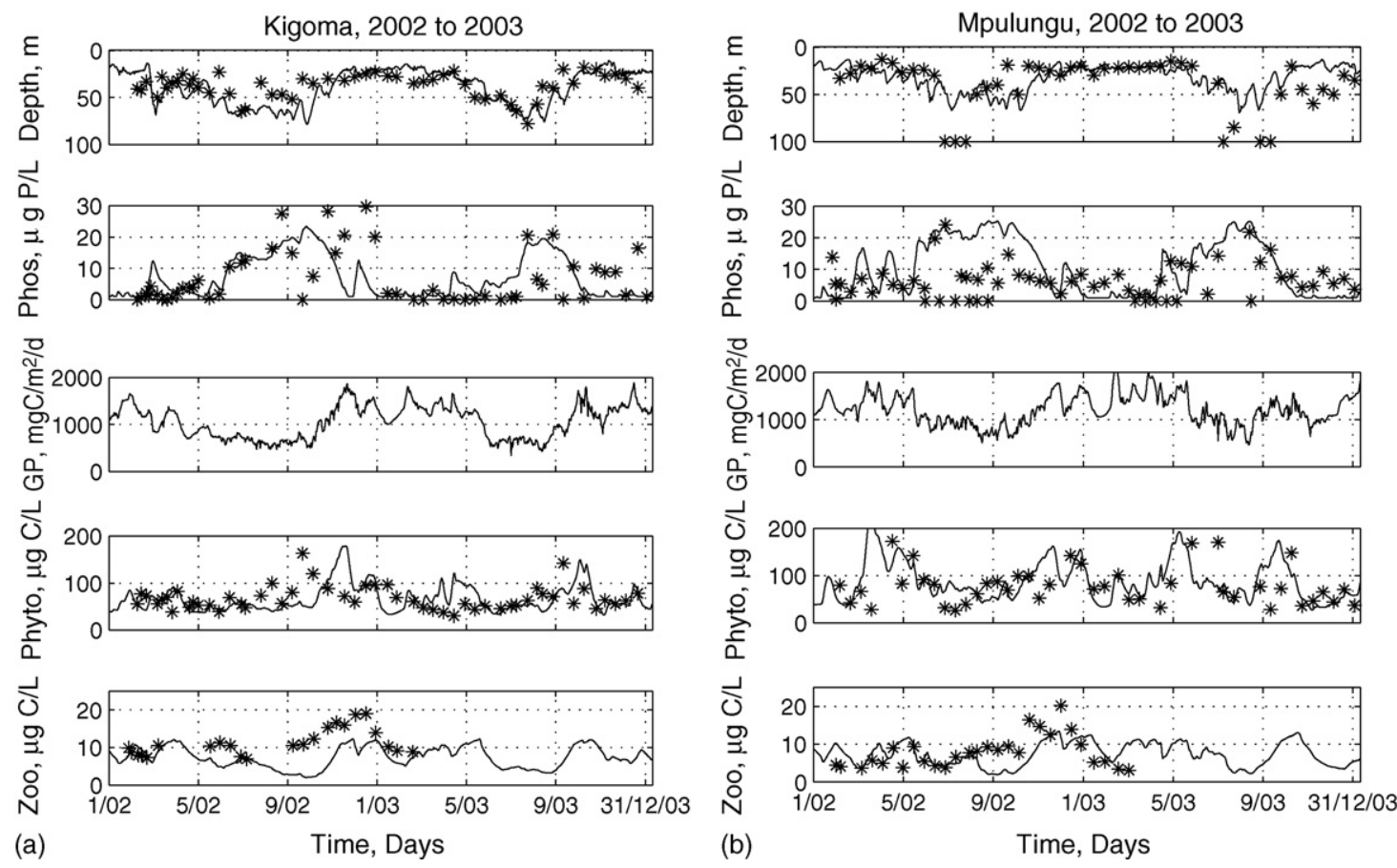

Fig. 5 - Ecological model output of the depth of the surface layer and the depth averaged values of phosphorus, gross production, and phytoplankton and zooplankton biomass in the surface layer for Kigoma and Mpulungu. Measurements are shown with stars.

beginning of strong wind season due to upwelling of nutrients from below, remains high for the rest of the dry season because of almost continuous upwelling and decreases at the beginning of the wet season. Increase in the biomass of phytoplankton at the beginning of the dry season is natural because of the input of nutrients in the surface layer. However, the phytoplankton biomass cannot sustain at this high value and decreases in spite of the continuous abundance of nutrients. This is because of the increased depth of the surface layer the phytoplankton is now subject to light-limitation. Phytoplankton biomass shows another bloom at the end of the dry season when there are still enough nutrients and the surface layer depth is shallower. Phytoplankton biomass seems to exhibit a very good compromising dependency on nutrient-limitation and light-limitation.

A simple ecological model coupled to a hydrodynamic model successfully predicted the dynamics of primary productivity in Lake Tanganyika during 2002-2003. There are dif- ferences between simulations and observations, they are relatively small, and can be attributed to a number of factors, including the fact that a uniform wind stress was assumed over the whole lake, and that nutrient inputs from rain and rivers were neglected. Despite the shortcoming of the model, the range of predicted plankton biomass is well in the range of observed data and the variation of phytoplankton biomass is correctly represented. Given that the model includes only one nutrient and does not detail phytoplankton components at this stage, simulated variables show a reasonably good relation with the measurements or biomass estimates.

While the ecological sub-model is simple, the agreement between observations and predictions is encouraging. Our results are in agreement with earlier studies indicating that Lake Tanganyika phytoplankton is confronted with restricted nutrient supply (Edmond et al., 1993; Hecky et al., 1993; Järvinen et al., 1999). The estimate of primary productivity is within the range of values given by Hecky and Fee (1981),

Table 2 - Percentage change in various ecological parameters during various sensitivity tests with $k_{\text {phyto }}$ and zooplanktivorous fish population $(F)$ as compared to the control run

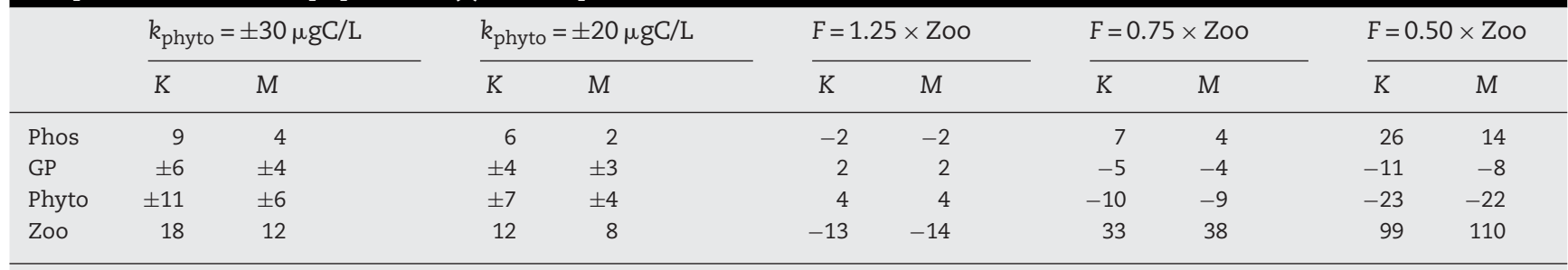

$\mathrm{K}$ and $\mathrm{M}$ respectively are the sites off Kigoma and Mpulungu. 

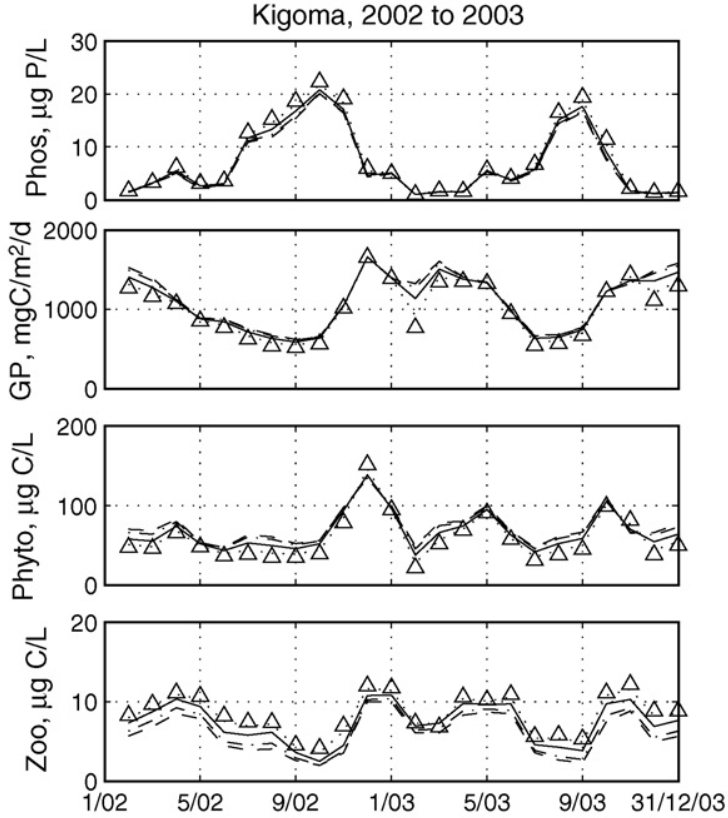

(a)

Time, Days
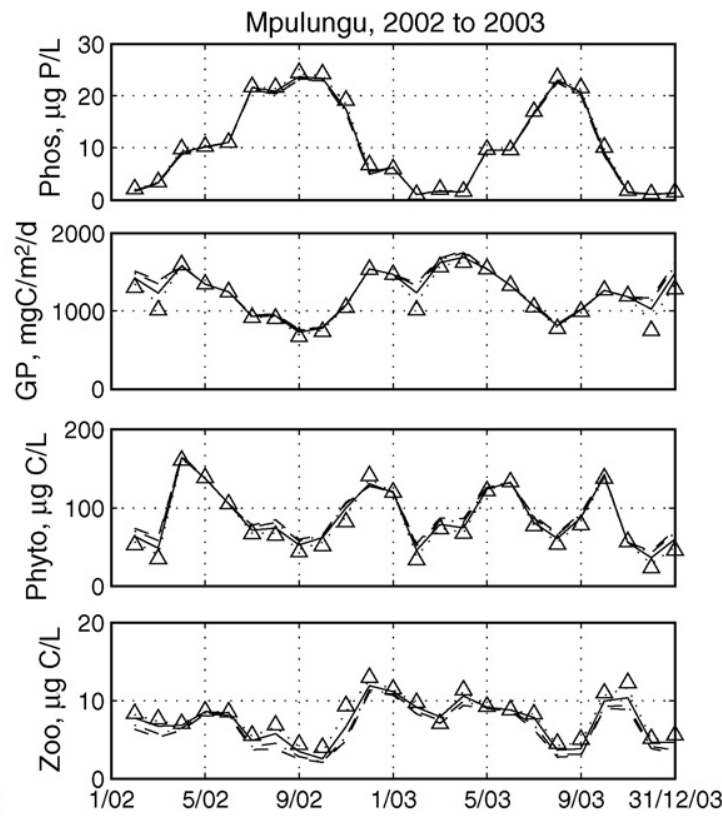

(b)

Time, Days

Fig. 6 - Monthly averages of the depth of the surface layer and the depth averaged values of phosphorus, gross production, Phytoplankton and Zooplankton biomass in the surface layer off Kigoma and Mpulungu for $k_{\text {phyto }}=30 \mu g C / L$ (solid), $k_{\text {phyto }}=39 \mu \mathrm{gC} / \mathrm{L}$ (dash), $k_{\text {phyto }}=36 \mu \mathrm{gC} / \mathrm{L}$ (dash-dot), $k_{\text {phyto }}=24 \mu \mathrm{gC} / \mathrm{L}$ (dotted) and $k_{\text {phyto }}=21 \mu \mathrm{gC} / \mathrm{L}(\wedge)$.

Sarvala et al. (1999) and Langenberg et al. (2003b). Another interesting result from the sensitivity analyses is that the primary production, which strongly depends upon the light in the water column and entrainment of nutrients, is bottom-up controlled. While, it seems that predator abundance strongly controls zooplankton biomass (top-down control). By contrast, fish predation influence seems reduced on the phytoplankton level. In other words, any change in predator biomass significantly affects the herbivore biomass, but has little influence on phytoplankton biomass. Indeed, in our simulations, reduced
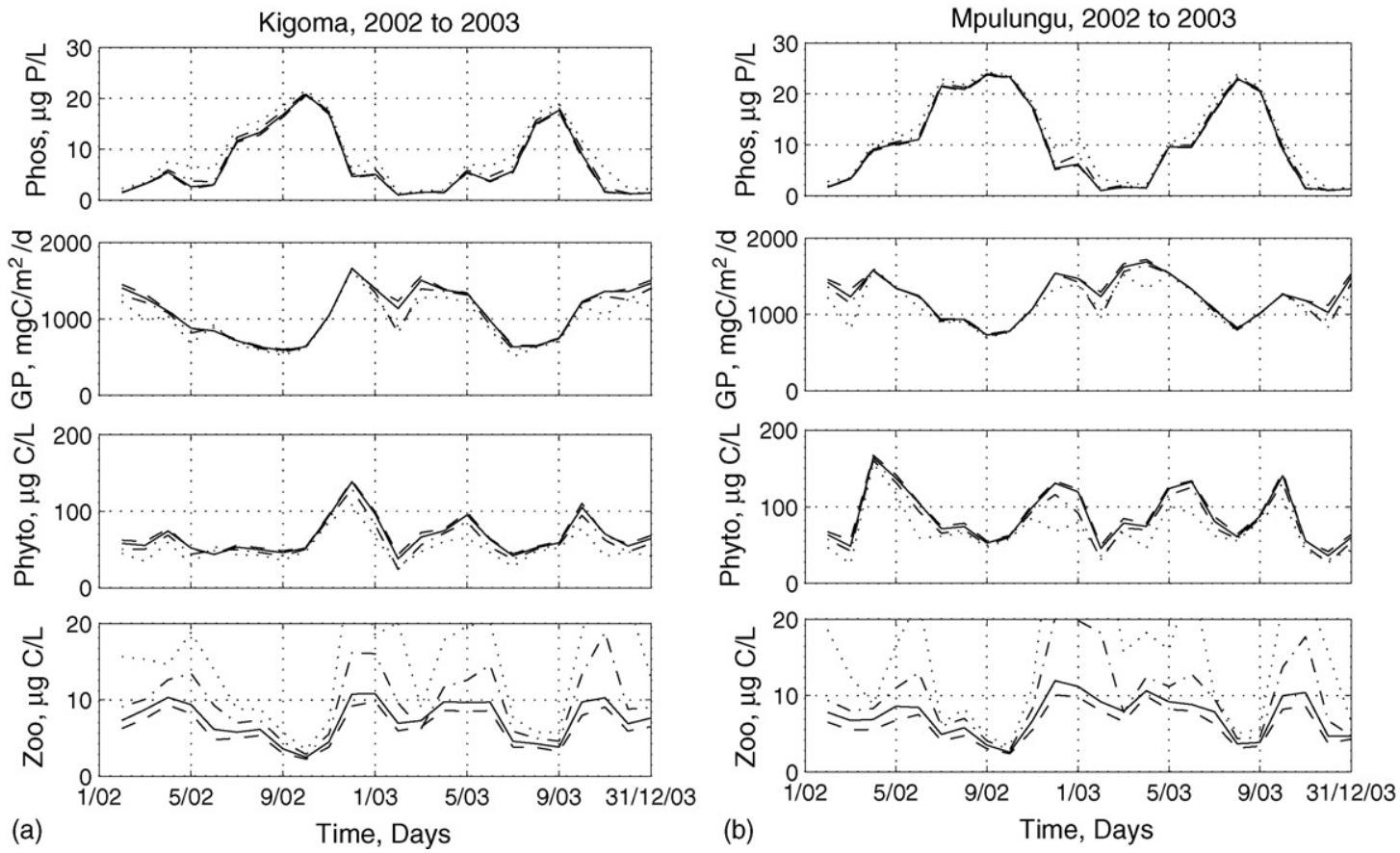

Fig. 7 - Same as Fig. 6 for predator biomass equal to zooplankton biomass (solid), predator biomass more than $25 \%$ of zooplankton biomass (dash), predator biomass less than $25 \%$ of zooplankton biomass (dash-dot) and predator biomass half of zooplankton biomass (dotted). 
grazing pressure from top to down control of mesozooplankton did not increase phytoplankton abundance considerably. This is similar to the conclusion made by Järvinen et al. (1999) that in planktivore dominated Lake Tanganyika zooplankton are not able to control phytoplankton, and therefore, light or nutrient limitation and resource competition seem to be common among the latter. This should be, however, verified by further field studies on the actual grazing pressure exerted by mesozooplankton, and by surveys of fish populations accurate enough to provide estimates of predation by planktivorous fish.

\section{Conclusions}

This work demonstrates that the biological productivity of Lake Tanganyika can be assessed by ECOH model. The study shows that the lake is not eutrophicated, as is apparent by the high visibility and the small values of phytoplankton concentration. As reported by earlier studies the understanding of the inter-relationship between hydrological and ecological processes will help on the design of procedures for the management of Lake Tanganyika resources and fisheries (Coulter, 1977; Hecky, 1984). The upwelling-productivity relationship addressed by the ECOH model can be used to address the impact of physical and climatological processes on the ecological behaviour of the Lake and to construct its past climatological biological productivity. The model can be further exploited for the paleolimnological studies of the Lake.

\section{Acknowledgments}

This work was carried out for the project 'Climate Variability as Recorded by Lake Tanganyika' (CLIMLAKE), funded by the Belgian program of Sustainable Development under contract EV/10/2D (Belgian Science Policy). Eric Deleersnijder is a Research Associate with the Belgian National Fund for Scientific Research (FNRS).

\section{REFERENCES}

Ahlgren, I., Frisk, T., Kamp-Nielsen, L., 1998. Empirical and theoretical models of phosphorus loading, retention and concentration versus trophic state. Hydrobiology 170, 285-303.

Bonnet, M.P., Wessen, K., 2001. ELMO, a 3-d water quality model for nutrients and chlorophyll: first application on a lacustrine ecosystem. Ecol. Model. 141, 19-33.

Coulter, G.W., 1977. Approaches to estimating fish biomass and potential yield in Lake Tanganyika. J. Fish Biol. 11, 393-408.

Coulter, G.W., Spigel, R.H., 1991. Hydrodynamics. In: Coulter, G.W. (Ed.), Lake Tanganyika and its Life. Oxford University Press, London, pp. 49-75.

Descy, J.-P., Gosselain, V., 2004. CLIMLAKE progress report 2002. Press Universitaires de Namur, p. 73.

Descy, J.-P., Hardy, M.A., Stenuite, S., Pirlot, S., Leporcq, B., Kimirel, I., Sekadende, B., Mwaitega, S.R., Sinyenza, D., 2005.

Phytoplankton pigments and community composition in Lake Tanganyika. Freshwater Biol. 50, 668-684.

Edmond, J.M., Stallard, R.F., Craig, H., Craig, V., Weiss, R.F., Coulter, G.W., 1993. Nutrient chemistry of water column of Lake Tanganyika. Limnol. Oceanogr. 38, 725-738.
Elser, J.J., Foster, D.K., Hecky, R.E., 1995. Effects of zooplankton sedimentation in pelagic ecosystem: theory and test in two lakes of the Canadian Shield. Biogeochemistry 30, 143-170.

Hamilton, D.P., Schladow, S.G., 1997. Prediction of water quality in lakes and reservoirs Part I-model description. Ecol. Model. 96, 91-110.

Handoh, I.C., Bigg, G.R., 2001. Use of a reduced-gravity model to evaluate present and past primary productivity in the tropical open ocean. Limnol. Oceanogr. 46 (7), 1632-1641.

Hecky, R.E., 1984. African lakes and their trophic efficiencies: a temporal perspective, Trophic Interactions within Aquatic Ecosystems. AAAS Select. Symp., vol. 85. Westview, p. 405-488.

Hecky, R.E., Fee, E.J., 1981. Primary production and rates of algal growth in Lake Tanganyika. Limnol. Oceanogr. 26, 532-547.

Hecky, R.E., Spigel, R.H., Coulter, G.W., 1991. Hydrodynamics. In: Coulter, G.W. (Ed.), Lake Tanganyika and its Life. Oxford University Press, London, pp. 76-89.

Hecky, R.E., Campbell, P., Hendzel, L.L., 1993. The stoichiometry of carbon, nitrogen and phosphorus in particulate matter of Lake Tanganyika. Limnol. Oceanogr. 38, 709-724.

Järvinen, M., Salonen, K., Sarvala, J., Vuorio, K., Virtanen, A., 1999. The stoichiometry of particulate nutrients in Lake Tanganyika-implications for nutrient limitation of phytoplankton. Hydrobiologia 407, 81-88.

Jorgensen, S.E., Kamp-Nielsen, L., Jorgensen, L.A., 1986 Examination of the generality of eutropication models. Ecol. Model. 32, 251-266.

Jorgensen, S.E., Bendoricchio, G., 2001. Fundamentals of Ecological Modelling. Elsevier, pp. 530.

Karagounis, L., Trosch, J., Zamboni, F., 1993. A coupled physical biochemical lake model for forecasting water quality. Aquat. Sci. 55, 87-102.

Langenberg, V., Nyamushahu, S., Rooijackers, R., Koelmans, A.A., 2003a. External nutrient sources for Lake Tanganyika. J. Great Lakes Res. 29, 169-180.

Langenberg, V., Sarvala, J., Roijackers, R., 2003b. Effect of wind induced water movements on nutrients, chlorophyll-a, and primary production in Lake Tanganyika. Aquat. Ecosyst. Health Manage. 6 (3), 279-288.

Mieleitner, J., Reichert, P., 2006. Analysis of the transferability of a biogeochemical lake model to lakes of different trophic state. Ecol. Model. 194, 49-61.

Naithani, J., Deleersnijder, E., Plisnier, P.-D., 2002. Origin of intraseasonal variability in Lake Tanganyika. Geo. Res. Lett. 29 doi:10.1029/2002GL015843.

Naithani, J., Deleersnijder, E., Plisnier, P.-D., 2003. Analysis of wind-induced thermocline oscillations of Lake Tanganyika. Environ. Fluid Mech. 3, 23-39.

Naithani, J., Deleersnijder, E., 2004. Are there internal Kelvin waves in Lake Tanganyika? Geophys. Res. Lett. 31 doi:10.1029/2003GL019156.

Pers, B.C., Persson, I., 2003. Simulation of a biogeochemical model in different lakes. Nordic Hydrol. 34 (5), 543-558.

Price, J.F., 1979. On the scaling of stress-driven entrainment experiments. J. Fluid Mech. 90, 509-529.

Reynolds, C.S., Irish, A.E., 1997. Modelling phytoplankton dynamics in lakes and reservoirs: the problems of in-situ growth rates. Hydrobiologia 349, 5-17.

Sarvala, J., Salonen, K., Jarvinen, M., Aro, E., Huttula, T., Kotilainen, P., Kurki, H., Langenberg, V., Mannini, P., Peltonen, A., Plisnier, P.-D., Vuorinen, I., Molsa, H., Lindqvist, O.V., 1999. Trophic structure of Lake Tanganyika: carbon flows in the pelagic food web. Hydrobiologia 407, 149-173.

Verburg, P., Hecky, R.E., 2003. Wind patterns, evaporation and related physical variables in Lake Tanganyika. East Africa. J. Great Lakes Res. 29, 48-61.

Verburg, P., Hecky, R.E., Kling, H., 2003. Ecological consequences of a century of warming in Lake Tanganyika. Science 301, 505-507. 